\title{
Obituary
}

\section{Kookal Ramunni Krishnan}

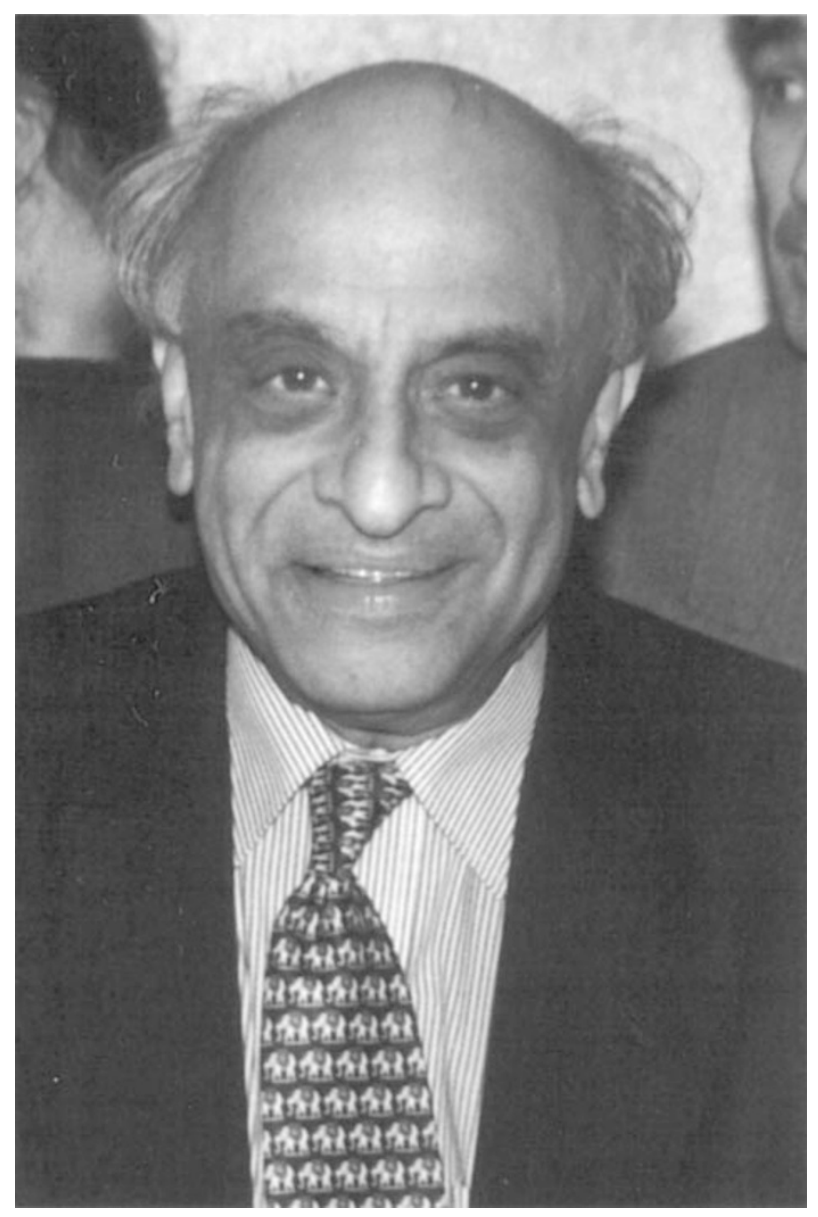

Krishnan worked, and for a time with Sir Ludwig Guttman. It was during this time that he developed his understanding and concern for those with spinal cord injury. Following a brief period in India he was persuaded to return to England in 1971 to take on the vacant post of Consultant in Spinal Injuries in Southport. He undertook this post with great enthusiasm and developed the service extensively. He always kept the interests of his patients paramount, acting as their strongest advocate, not only for their needs but also for those of their family and friends. Krishan set exacting standards to ensure a balance was always achieved between their clinical, personal and family needs; he had an unfailing ability to remember the names of patients and their families who returned to the Centre many years after their initial discharge. His persuasive personality and dedication to the benefit of patients remains at the core of practice in Southport Centre to the present day.

The development and opening of a purpose built Spinal Injuries Centre in Southport in 1991, arose out of Krishnan's dedication, charisma and vision to ensure the best possible service to his patients. His dedication to providing comprehensive service for those with spinal cord injury led to, amongst many achievements, appointment of the first dedicated clinical psychology service to a spinal injuries unit; case management initiatives to manage the process of care and community reintegration; development of life-long follow-up programmes and management in the community to ensure continued health; the development of purpose-built accommodation in order to enable people to live independently, and funding a chalet so patients and their families might take holidays together in safety and comfort.

Krishnan was also the driving force for a wide Former Director and Consultant in charge of the Regional Spinal Injuries Centre, Southport, Merseyside. Born in Kerela, India 1929, he died peacefully in his sleep on 28th December 1999. Known to everyone with whom he came into contact as Krishnan or Krish, he first practised medicine in the Indian Army and subsequently trained as a neurosurgeon in England.

His father, a High Court Judge in Kerela, had encouraged him to travel to England 'To get to know the English'. Those who met and talked with Krishnan will no doubt realise that he did indeed achieve this aim, probably more than the English as a nation understand themselves. He managed this achievement through close observation of human behaviour, his warmth, witty intelligence, and his humour will be sadly missed. range of technological developments within the Centre. He developed and promoted care for those with spinal cord injury so severe as to render them permanently ventilator-dependent and developed internationally recognised services to such an extent that it is now the norm for such people to return home with comprehensive care. Krishnan also developed Rehabilitation Technology services to enable mobilisation, and even after retirement in 1995 continued with the Presidency of the CALIES project, a pan-European venture to pioneer mobility using implanted muscle stimulation. This programme plans to undertake the world's first implanted system for mobility later this year. 
As well as being a pre-eminent clinician, Krishnan was an established academic, holding appointments in the Department of Neurological Sciences at the University of Liverpool, and had recently been appointed a Professor by the Department of Rehabilitation Technology at the University of Salford. He had produced almost 100 peer reviewed publications, numerous invited chapters in a wide range of publications, and was in the process of writing a book on tetraplegic ventilatory management.

Retirement to Krishnan appeared simply to provide the opportunity to move the focus of his enthusiasm to new areas. He remained in great demand from solicitors and barristers for his persuasive advocacy on behalf of patients' personal injury claims. Indeed, many have commented they owe him a great deal for the effect he had on developing their own professional and personal understanding of the cases in which they are involved. He had begun to spend more time in his garden and had many plans for the coming season. The family kitchen was the hub of all activity and Krishnan was an excellent cook and host. Krishnan is survived by his wife Patsy, son Richard and daughter Anjali, and his sister Lola and brother Ayrton. His love of family and friends knew no bounds.

Krishnan was a visionary, humanitarian and master tactician. His clinical skill was unerringly accurate and purposeful. Those who received his training, and the people they treat, will continue to benefit from his support for many decades. He will be missed by all those whose lives he touched.

Colleagues and Friends of K Krishnan 